\title{
A (SUPOSTA) FALTA DE LEITURA DOS CAMPINENSES: UM DISCURSO NADA NOVO ${ }^{1}$
}

\section{THE (ALLEGED) LACK OF READING OF CAMPINENSES: A NOT SO NEW SPEECH}

\begin{abstract}
Danielly Vieira Inô*
Resumo:No presente artigo, pretendemos desenvolver uma reflexão sobre a existência ou não de leitores na cidade de Campina Grande-PB. Para discutir razoavelmente este tema, é essencial pensarmos sobre questões como: quem lê? O que lê? Como lê? E onde lê? O caminho escolhido para contribuirmos com as discussões em torno do tema foi o de relacionar essas perguntas a um espaço público de leitura, que existe na cidade de Campina Grande-PB desde 1938: a sua Biblioteca Púbica Municipal.Mas, dentro desse terreno movediço que são as práticas de leitura, especialmente aquelas realizadas em bibliotecas, pretendemos fazer um recorte que nos levará à Campina Grande dos anos 1950 e ao que se dizia nos jornais sobre o assunto. Mais especificamente, retomaremos textos que circularam nos jornais $O$ Momento (setembro/1950), Jornal Formação (outubro/1951 e outubro/1953), O Globo (julho/1952 e agosto/1952), Jornal do Estudante (agosto/1953), e que se dedicaram a discutir se e $o$ que se lia na cidade, sobretudo em sua Biblioteca Pública Municipal. Serão analisados ao todo 06 (seis) textos, com o objetivo de verificar que concepções de leitura e leitores estavam subjacentes a eles, ao mencionarem as práticas desenvolvidas naquele espaço.
\end{abstract}

Palavras-chave: Leitura. Biblioteca. Leitores

\begin{abstract}
In the present article, we intend to develop a reflection about the existence or not of readers in the city of Campina Grande-PB. To reasonably discuss this topic, it is essential to think about such issues as: who reads? What is read? How the reading is done? And where does this reading take place? The path chosen to contribute to the discussions about this theme was to relate these questions to a public reading space, which has existed in the city of Campina Grande-PB since 1938: its Municipal Public Library. But, within this shifting ground of reading practices, especially those carried out in libraries, we intend to make a cut that will take us to Campina Grande of the 1950s and to what was said in the newspapers on the subject. More specifically, we will return to texts that circulated in newspapers such as O Momento (September / 1950), JornalFormação (October / 1951 and October / 1953), O Globo (July / 1952 and August / 1952), Jornal do Estudante that were dedicated to discuss if and what was read in the city, especially in its Municipal Public Library. A total of six (6) texts will be analysed in order to verify which concepts of reading and of reading were implied by them, when mentioning the practices developed in that space.
\end{abstract}

Keywords: Reading. Public Library. Readers

\section{Para início de conversa}

Diante do convite para participar de uma mesa redonda cujo tema está elaborado sob a forma de uma pergunta, imaginamos que a expectativa era de que nós, palestrantes, iríamos apresentar uma resposta. Bastaria, então, escolhermos entre o sim e o não e argumentarmos a favor do nosso posicionamento sobre Campina Grande ser ou não uma cidade de leitores. Contudo, essa tarefa não é tão simples quanto possa parecer,

\footnotetext{
${ }^{1}$ Este texto recupera parte das discussões realizadas pela autora na mesa redonda "Campina Grande: uma cidade leitora?", dentro da programação da I FLIC.

"Professora Doutora em Linguística pela Universidade Federal da Paraíba - Professora dos Cursos de Letras (Língua Portuguesa e Língua Espanhola) da Universidade Estadual da Paraíba. dany_vi@yahoo.com.br
} 
pois requer responder a outras questões que lhe são anteriores, como: o que significa ser leitor? Que critérios costumam ser levados em consideração para determinar a classificação de alguém como leitor ou não? E quem os determina (os critérios e as classificações)? As respostas a esses questionamentos, por sua vez, variam bastante, a depender de vários fatores, entre eles, a época e o respectivo contexto sócio-históricocultural.

É natural, no entanto, que olhemos para o tema de maneira anacrônica, a partir da perspectiva que, majoritariamente, partilhamos hoje. Neste sentido, a ideia, bastante difundida socialmente, é a de que um (bom) leitor seria aquele que lê muito, preferencialmente livros e livros de literatura (ao que parece, quanto mais próximos do cânone e mais distantes da lista dos best-sellers, melhor). Diante de um posicionamento como este, quem lê fenômenos literários como a saga Harry Potter, ou quem é fã de quadrinhos, ou ainda quem prefere ler poetas que publicam seus textos em sites e redes sociais, não seria considerado (bom) leitor. Apenas por essa comparação superficial já é possível perceber o quanto essa noção de leitura e de leitores é insuficiente para contemplar a diversidade de práticas que sempre existiram e se intensificaram recentemente com o avanço das tecnologias.

A discussão proposta pela mesa redonda da FLIC - "Campina Grande: uma cidade leitora?" - nos deu a oportunidade de problematizar essas noções, na busca por compreendermos se temos ou não uma cidade que lê. Mas, se quisermos refletir razoavelmente sobre o tema, é essencial pensarmos sobre questões como: quem lê? $\mathrm{O}$ que lê? Como lê? E onde lê? Como se pode perceber, temos muitas perguntas e, talvez, nem tantas respostas. O caminho escolhido para contribuirmos com essa reflexão foi o de relacionar essas perguntas a um espaço público de leitura, que existe na cidade de Campina Grande-PB desde 1938: a sua Biblioteca Púbica Municipal.

Mas, dentro desse terreno movediço que são as práticas de leitura, especialmente aquelas realizadas em bibliotecas, pretendemos fazer um recorte que nos levará à Campina Grande dos anos 1950 e ao que se dizia nos jornais sobre o assunto. Mais especificamente, retomaremos textos que circularam nos jornais $O$ Momento (setembro/1950), Jornal Formação (outubro/1951 e outubro/1953), O Globo (julho/1952 e agosto/1952), Jornal do Estudante (agosto/1953), e que se dedicaram a discutir se e $o$ que se lia na cidade, sobretudo em sua Biblioteca Pública Municipal. Serão analisados ao todo 06 (seis) textos, com o objetivo de verificar que concepções de leitura e leitores estavam subjacentes a eles, ao mencionarem as práticas desenvolvidas naquele espaço.

O presente artigo, então, encontra-se dividido em duas partes principais: na primeira, serão discutidos fundamentos desse discurso sobre a leitura que nos falta; na segunda, serão analisados os textos sobre a Biblioteca de Campina Grande e sobre as práticas de seus leitores nesta instituição.

\section{Leitura em falta}

Na tentativa de descrever os leitores de biblioteca, bem como suas práticas de leitura, verificamos que ambos - leitores e práticas - só podem ser apreendidos, por vezes, através de relações indiretas ou suposições fundadas em documentos relacionados ao funcionamento das bibliotecas. Dificilmente, há o registro preciso de como eles liam nestas instituições ou a partir delas. Portanto, buscar essas práticas não deixa de ser uma operação de caça (CERTEAU, 1994), no qual o pesquisador conta apenas com sinais deixados indiretamente e desapercebidamente por esses leitores ou 
por documentos que focalizam a leitura de maneira geral. Nesse sentido, o trabalho do pesquisador aproxima-se do método proposto, no final do século XIX, pelo italiano Giovanni Morelli para a análise de pinturas: segundo retoma Ginzburg (2007), Morelli propõe que a autenticidade das obras seja verificada através da observação de características presentes em detalhes que costumeiramente não eram analisados pelos especialistas, tais como a forma de pintar o lóbulo da orelha ou as unhas. Ele acreditava ser necessário "examinar os pormenores mais negligenciáveis, e menos influenciados pelas características da escola a que o pintor pertencia" (GINZBURG, 2007, p. 144), pois estes eram mais difíceis de ser reproduzidos pelos falsificadores, justamente por não serem muito vistosos. Cabia ao especialista, então, buscar aí indícios da originalidade do estilo de cada pintor a fim de separar os quadros verdadeiros dos falsos.

Tendo em vista as raras referências aos leitores de biblioteca, deparamo-nos com a mesma necessidade de buscar as práticas desses leitores através dos "pormenores" que escapam nas histórias contadas sobre estes espaços de leitura, uma vez que os leitores não costumam, na maior parte dos textos, sermencionados. Essa ausência pode levar à falsa ideia de que esse leitor, efetivamente, não existia/existe. Alia-se a essa invisibilidade o fato de que os leitores, de forma geral, ao serem mencionados em textos nos quais se discute a leitura, costumam ter suas práticas negadas por serem consideradas inadequadas ou ilegítimas. Nesse caso, diz-se que não há leitores, mas na verdade o que não há são os "bons leitores" (ABREU, 2002): aqueles que lêem as leituras consideradas corretas, de forma adequada (em termos de gestos e de interpretações) e nos locais indicados. Nesse sentido, como os critérios para definir o que é um (bom) leitor variam consideravelmente, também é variável o discurso diante da existência ou não dessa figura.Segundo Abreu (2002),

\footnotetext{
Por detrás de afirmações corriqueiras nos dias atuais, como "ler é bom", há uma seleção implícita de um conjunto de obras que tornam "bom" o ato de ler e que justificam outras tantas afirmações, também bastante comuns, como "os jovens não têm o hábito da leitura". Na verdade, lê-se muito livro de auto-ajuda, de vulgarização científica, muita ficção científica, história em quadrinho, lê-se muito livro sobre hobby, sobre astros da música e do cinema, muitas recolhas de piadas. Mas lêem-se pouco os "bons livros": pouca filosofia, pouca literatura erudita, pouca reflexão política séria. Em resumo, parece haver uma diminuição do interesse pelos livros positivamente avaliados pela escola, pela academia, pela crítica literária. (p. 14-15).
}

Diante dessas leituras negativamente avaliadas, ocorre também a negativa da leitura e dos leitores, afirmando-se que aqui não se lê. Mas, como se sabe, nem sempre a leitura de literatura foi a prática considerada ideal e nem sempre um bom leitor era aquele que lia muito. O filósofo Arthur Schopenhauer, por exemplo, elaborou severas críticas, no século XIX, à leitura extensiva, que ganhava espaço com a multiplicação de impressos na Alemanha, e ao tipo de obra que se lia. Segundo ele, obras que fazem grande sucesso com as massas são de qualidade duvidosa e não contribuem para a reflexão crítica. Para este pensador, as pessoas deveriam ler menos, refletir mais detidamente sobre o que lêem e escolher as leituras não em função do sucesso de público que elas alcançaram ou pelo seu teor de novidade, mas pela sua inserção numa tradição e pela notoriedade alcançada pelo autor:

Como as pessoas lêem sempre, em vez dos melhores de todos os tempos, apenas a última novidade, os escritores permanecem no círculo estreito das 
idéias que circulam, e a época afunda cada vez mais em sua própria lama. Por isso é tão importante, em relação ao nosso hábito de leitura, a arte de nãoler. Ela consiste na atitude de não escolher para ler o que, cada momento determinado, constitui ocupação do grande público; por exemplo, panfletos políticos ou literários, romances, poesias etc., que causam rebuliço justamente naquele momento e chegam a ter várias edições em seu primeiro e último ano de vida. Basta nos lembrar de que, em geral, quem escreve para os tolos encontra sempre um grande público, a fim de que nosso tempo destinado à leitura, que costuma ser escasso, seja voltado exclusivamente para as obras dos grandes espíritos de todos os tempos e povos, para os homens que se destacam em relação ao resto da humanidade e que são apontados como tais pela voz da notoriedade. Apenas esses espíritos realmente educam e formam os demais. (SCHOPENHAUER, 2010, p. 132133. Grifos do autor)

É evidente, portanto, uma escolha por práticas de leitura específicas: há aí uma indicação sobre qual é a leitura considerada mais adequada e sobre qual a forma correta de realizá-la. Além disso, é interessante observar que, na recusa em relação ao que se lê e como se lê na Alemanha do século XIX, Schopenhauer acaba dando indícios de que a leitura era uma prática bastante comum, que ela acontecia nas camadas mais populares e com grande frequência e intensidade. O problema, para ele, estava na escolha do que ler e do como ler, ou seja, as pessoas liam, mas liam as obras erradas e do modo errado. Seu principal argumento é o de que uma obra, desde que atinja a popularidade, passa a ser considerada uma obra de qualidade duvidosa, pois ele parte do raciocínio de que, se agradou a diferentes grupos sociais, é porque é uma obra para "tolos" e, portanto, não deve ser lida por quem desejar "elevar seu espírito". Assim, leitura boa é a leitura de uma certa elite, leitura a que poucos têm acesso e que poucos conseguem decifrar.

Não deixa de ser, então, uma tentativa de reforçar o poder através da leitura: se esta chega a todos, indiferenciadamente, não pode ser considerada boa; se muitos lêem e lêem muito, também não é uma boa prática. Separando as obras em boas e ruins, ele completa:

Quanto às obras ruins, nunca se lerá pouco quando se trata delas; quanto às boas, nunca elas serão lidas com freqüência excessiva. Livros ruins são veneno intelectual, capaz de fazer definhar o espírito.

Para ler o que é bom uma condição é não ler o que é ruim, pois a vida é curta, o tempo e a energia são limitados.(SCHOPENHAUER, 2010, p. 133.)

Uma evidência de que são variáveis os critérios que levam a considerar uma leitura como boa ou ruim está numa publicação realizada no jornal Voz da Borborema, no qual o jornalista comenta a obra de Monteiro Lobato, História do Mundo para Crianças (publicada em 1933). A obra é uma adaptação, destinada ao público infantil, da história da evolução humana, desde a formação da Terra até a Segunda Guerra Mundial. A clara referência à teoria evolucionista, de Charles Darwin, parece ser o que causa maior indignação no autor do texto jornalístico (que não é identificado pelo jornal), como se pode perceber no fragmento a seguir:

Sob o ponto de vista doutrinario, é profundamente lamentável o desamor e a incúria do Sr. Monteiro Lobato em se servindo de as vasta intelligencia e capacidade para illustrar encantadoramente um livro que logo no princípio traz conceitos que ferem fortemente a doutrina christianizada. $\mathrm{O}$ ponto culminante de suas falsas idéas que merece justos protestos da parte dos escriptorescatholicos, é a sua desmedida espontaneidade quando diz 
publicamente que o homem teve origem simiana, pois, apresenta o homem como originário de um ser bruto - o macaco - e não ter pêjo de oppor-se à bellíssima narração da Sagrada Escriptura sobre o homem primitivo. (Voz da Borborema, 3 de novembro de 1937)

O autor, claramente, fala a partir de um posicionamento orientado pela religião católica e traz para o seu texto a discussão entre a teoria criacionista e a evolucionista sobre a origem do mundo. Segundo a sua perspectiva, apesar do reconhecido valor de Monteiro Lobato, a leitura do seu livro seria prejudicial às crianças, juízo que leva o seu resenhista a não recomendar essa obra e até mesmo condená-la:

[...] Por que o sr. Monteiro Lobato não se serve do seu grandioso talento literário, consagrando-o a uma causa mais elevada?

Será que elle se serve da fertilissima imaginação da criança incauta, infiltrando-lhe princípios extravagantes e illusórios?

Em synthese, a "História do mundo para crianças" é um livro tal e qual a comparação feita por um outro escriptorcatholico: "É como certas farinhas alimentícias: agradam, mas, fazem mal.

(Voz da Borborema, 3 de novembro de 1937)

$\mathrm{O}$ argumento defendido pelo autor desse texto que condena Monteiro Lobato aproxima-se daquele defendido por Schopenhauer (2010), retomado anteriormente, e foi verificado por Abreu (2002) também nos tratados setecentistas:

$\mathrm{O}$ verdadeiro belo, o verdadeiro bom, é aquilo que agrada àqueles que têm muito espírito e gosto. [...] Mas freqüentemente aquilo que agrada muito àqueles que têm muito espírito e gosto, agrada menos, ou mesmo não agrada absolutamente àqueles que o têm em menor quantidade, e é bem natural que seja assim. O bom gosto em todas as matérias não é de forma alguma o gosto da maioria em geral, é gosto do maior número daqueles que têm as qualidades, os conhecimentos, a experiência necessária para julgar bem a matéria de que se trata; é, se posso me exprimir assim, o gosto mais comum entre as pessoas menos comuns. (tratado setecentista recuperado por ABREU, 2002, p. 218)

Por vezes, a suposta "leitura ruim" ou "errada" é equiparada à falta de leitura, ou seja, as práticas de quem lê aquelas obras consideradas ilegítimas e/ou o faz da maneira também considerada inadequada acabam sendo negadas e com base nessa negativa constrói-se a afirmação de que não há leituras nem leitores.

No Brasil, há muito tempo o discurso sobre a leitura tem sido o da falta e veio se concretizando de diferentes maneiras: seja nos relatos de viajantes europeus que vieram ao país no século XIX (ABREU, 2001); ou nos relatos de visitantes à Biblioteca Nacional do Rio de Janeiro nesse mesmo período (LAJOLO; ZILBERMAN, 2009); ou ainda nos jornais da época e, mais recentemente, nas diversas campanhas de incentivo à leitura no país (se não há leitores, é preciso formá-los). Contudo, para não nos juntarmos aos pessimistas e fazermos coro ao seu eco de que não há leitores, é preciso analisar com cuidado as razões de seus lamentos e a noção de leitura que as orienta. Neste item, seguindo o caminho trilhado por Sousa (2011), discutiremos essa gênese do discurso da leitura como o discurso da falta, para, em seguida, relacionarmo-lo às notícias de jornal publicadas na década de 1950 sobre a Biblioteca Municipal de Campina Grande, as quais contribuem para formar uma imagem bastante distinta daquela registrada pelo jornal $A$ Voz da Borborema, no primeiro ano de existência deste espaço de leitura. 
Abreu (2001, p. 142), ao recuperar os relatos de viajantes, observa que todos referem-se à ausência da leitura e de uma vida letrada no Brasil. Mas a autora alerta para o fato de que

Tais viajantes eram europeus, frequentemente muito cultivados, que tomavam a alta cultura européia como parâmetro para suas avaliações. Para eles, a cultura revestia-se de alguns ícones: a abundância de livros presentes em bibliotecas ou espalhadas pelas casas, a freqüentação assídua a eles, sua sintonia com os avanços das ciências e das artes. Tinham em mente um tipo de leitura e de livro particulares.

Os critérios, portanto, para avaliar a existência de leitores e de uma cultura letrada no Brasil eram baseados no acesso a essa cultura e nos usos do livro tais como construídos nos moldes europeus. Além disso, não era o acesso e uso de qualquer livro, mas daqueles em "sintonia com os avanços das ciências e das artes", o que nos permite no mínimo olhar com ressalvas à afirmação de que não há leitores. É preciso considerar ainda que a realidade que servia de modelo para os viajantes era bem distinta daquela encontrada no Brasil do séc. XIX, ondehavia um grande número de analfabetos, era reduzido o número de escolas públicas e menor ainda o de bibliotecas ${ }^{2}$. Contudo, pela própria natureza dessas bibliotecas (destinadas às vezes a um público específico e nem todas abertas ao público) e pela constituição de seus acervos (formados principalmente por obras clássicas, publicadas em línguas estrangeiras, fato exaltado pelos viajantes), pode-se imaginar que sua frequência não era realmente comparável à de bibliotecas da Europa.

Por essa razão, os relatos de visitantes à Biblioteca Nacional do Rio de Janeiro no séc. XIX reforçam o coro: não há leitores!. De acordo com documentos recuperados por Lajolo e Zilberman (2009), a maior parte desses visitantes ressalta as boas instalações da biblioteca, a grandiosidade de seu acervo e o fato de que é aberto livremente para consulta do público. Paralelamente aos elogios, há sempre o lamento sobre a ausência de leitores: "[...] aqui é tão pouco sentida a importância das ocupações literárias, que as salas permanecem, por assim dizer, vazias" (SPIX; MARTIUS, apud LAJOLO; ZILBERMAN, 2009, p. 177). Ou ainda, como afirmou Thomas Ewbank a partir de viagem feita ao Brasil em 1844: “[...] cada pessoa decentemente vestida, branca ou preta, tem acesso livre à consulta [...]. Raramente encontrei ali mais de meia dúzia de consulentes [...]." (LAJOLO; ZILBERMAN, 2009 p.180). Ora, encontrar os salões "por assim dizer" vazios, não é o mesmo que encontrá-los efetivamente vazios; "raramente" encontrar "mais de meia dúzia de consulentes" não significa que estes não existiam, que estes leitores não frequentavam a Biblioteca Nacional (talvez houvesse até um número significativo deles, se considerarmos o contexto).

Quase 50 anos depois desses relatos, na última década do século XIX, brasileiros "das letras" (como jornalistas e escritores) passam a corroborar o discurso da falta de leitura no Brasil. Em texto sobre a produção e o consumo de literatura no país, intitulado "Decadencialitteraria" e publicado no jornal Estado da Parahyba ${ }^{3}$ de 1891, lê-se:

\footnotetext{
${ }^{2}$ No Rio de Janeiro, eram apenas 04 (quatro): a Biblioteca Nacional (1814); a Biblioteca do Convento São Bento; o Gabinete de Leitura do Rio de Janeiro (1837); e a Biblioteca do Instituto Histórico e Geográfico Brasileiro (1838) (LAJOLO; ZILBERMAN, 2009, p. 181). No Nordeste, a primeira biblioteca pública é a da Bahia, criada em 1839; e, na Paraíba, a Bibliotheca Pública da Parahyba, fundada em 1857, na cidade de Parahyba do Norte, hoje denominada João Pessoa.

${ }^{3}$ Disponível em http://www.cchla.ufpb.br/jornaisefolhetins/index.html
} 
Valentim Magalhães lamenta, pelas columnas do Paiz em seu numero de hoje a decadência em que decliva a arte da escripta no Brazil.

Lamenta e encontra os motivos desta apathia, ou melhor, desta terrível preguiça, que nos consome a vibratibilidade artística.

"Falta de meio, impropriedade de ambiente. Na capital onde se concentrava quasi todo o movimento litterario do paiz não ha logar para as lettras e a febre do dinheiro, a carestia da vida, a desocupação das coisas da arte e a preocupação das da bolsa por parte do publico produziram a baixa na procura e, portanto, na producção.

Quase ninguem lê e, pois, quase ninguem escreve."

Afirma. E em parte tem razão. Quase ninguem lê, disse bem, porque a leitura na sociedade brazileira é uma massada a quem poucos se dedicam. Ler, para o brazileiro, equivale a caceteação, synonimo que, mais tarde, abrirá admirativamente os olhos aos lexicologos.

Nas finas sociedades européas, discute-se litteratura e arte, na sociedade fluminense discute-se os preços dos vestidos, a raça dos cavallos e a belleza das carruagens compradas a pretenciosa burguezia arruinada do Rio da Prata. $[\ldots]$

Não ha sujeito favorecido pelos azares do jogo da bolsa que não possua dez anneis de brilhantes e outros tantos, alfinetes de gravata, um cavallo de raça, um [ilegível] e algumas duzias de vestuario. Ora, quem possue tantos brilhantes e tão grande numero de roupas, precisa exhibir-se e enquanto sae à rua em direcção ao passeio vespertino, ao hotel ou ao theatro, depois da labutação diurna que transforma esse gentlemam em moço de recados, não tem tempo para ler. E, de mais, a leitura é desnesesaria a tal gente. (Estado da parahyba, 19/07/1891, p. 3)

Como se vê, o jornalista de o Estado da Parahyba une-se ao de o Paiz para afirmar que no Brasil não há leitores e que a leitura é substituída por futilidades.Segundo o ponto de vista defendido no texto: as classes ricas não se interessam pela leitura, mas apenas pela vaidade alimentada pelos luxos frívolos ("os preços dos vestidos, a raça dos cavallos e a belleza das carruagens"), valorizados por seu grupo social; ou se desinteressam pela arte por terem outras preocupações ("a febre do dinheiro, a carestia da vida, a desocupação das coisas da arte e a preocupação das da bolsa por parte do publico") ou por preguiça ("desta terrível preguiça, que nos consome a vibratibilidade artística"); ou ainda por falta de tempo ("não tem tempo para ler").

No discurso desses jornalistas, fica claro que a leitura valorizada, mas não realizada pelos brasileiros, é a leitura de literatura e artes; portanto, subjacente a essa informação de que não há leitores no Brasil está a ideia de que a leitura a ser feita é a de litteratura e arte, o que se concretiza a partir de várias expressões utilizadas no texto para se referir à leitura que não é, mas deveria ser feita: "nos consome a vibratibilidade artística; Na capital onde se concentrava quasi todo o movimento litterario do paiz não ha logar para as lettras; Nas finas sociedades européas, discute-se litteratura e arte".

Seu discurso, então, é orientado por essa concepção que leva os jornalistas a, possivelmente, negarem outras formas ou tipos de leitura realizados pelos brasileiros nesse período. Além disso, é importante observar que os autores desse texto estão se referindo à prática da leitura em apenas uma classe social - a elite -, cujos interesses são descritos como frívolos, por haver, segundo eles, um interesse excessivo com a aparência e nenhum interesse pela leitura. As práticas de leitura das classes menos favorecidas, são, então, ignoradas nesse comentário divulgado no jornal.

No entanto, no mesmo texto em que se lamenta o fato de que aqui não se lê, o jornalista reconhece a produção de literatura no país e a resistência de escritores que, 
ainda que mal pagos, dedicam-se à criação de prosa e versos:

Ainda assim, apezar dessa indiferença das classes ricas pelas artes, os nossos prosadores e poetas não esmoreceram. Não ha leitores, não ha livros; mas trabalha-se em segredo trabalha-se convictamente se bem que todo o trabalho fique na gaveta, pois os editores metamorphosearam-se em emissores, e os miseraveis ordenados de jornalismo não dão para a temeridade de uma publicação, nem desses [ilegível] feito às pressas sae um com a alma dos Mecenas.

Que melhor prova quer Valentim Magalhães que o aparecimento desses dois ânos livros - o de Coelho Netto e o de Domicio da Gama?

E, pouco? Mas a época é de emissões, não de edições, [sic]

E quantas obras anunciadas não temos?

Raul Pompeia está com um livro quasiprompto - Agonia.

Mallet tem um trabalho - O prélo e Olavo Bilac um livro de poesias; Aluizo prepara um novo romance; Lima Campos, orignalissimo prosador moderno, burilos os últimos capítulos do Atravéz; Cruz e Souza, esse bello artista de [ilegível] que produz phrases sonoras como crystaes, rutilantes como astros organisa um livro de contos Virgilio, Vazea entregou ao prelo os Campos e Mares. Arthur de Miranda, que é um artista dedicadíssimo dá o último lavor a um livro de estréa intitulado [Naturais] e Silhuetas; Sylvio Freire revê as provas das [Timidas] e [trecho ilegível] exquisito sentimento de decadente, um excellente livro de versos, quentes como os vinhos de [ilegível] aromaticos como a myrra d'Oriente.

Que mais desejar, nesses tempo?

Bem sabemos que podíamos adiantar mais alguns passos, mais Valentim conhece bem o nosso publico para comprehender as deffeculdades com que se lucta.

Enquanto a censura aos artistas que desertaram da imprensa diária, é injusta. Fazer litteratura em jornal é muito bom quando o jornal paga generosamente o trabalho; mas fazer prosa e cosinhar ao mesmo tempo, à rasão de cento e cincoenta ou duzentos mil reis por mês e dependendo assim das imposições dos proprietários dos jornaes é impossível.

Tudo quanto se fizer ha de sair descosido, remendado, torto, como essas linhas que ahi ficam. (Estado da Parahyba, 19/07/1891, p. 3)

A ausência de leitores, tão lamentada no texto, promove, segundo essa publicação, a decadência literária anunciada no título do artigo. E essa decadência se reflete tanto na produção literária (em termos de quantidade e qualidade) quanto na própria valorização do ofício de escritor: os escritores são mal remunerados e, consequentemente, por não poderem dedicar-se exclusivamente à "arte da escripta", veem cair a qualidade de sua produção, uma vez que "os miseraveis ordenados de jornalismo não dão para a temeridade de uma publicação". E, sobre esse aspecto, merece destaque a afirmação de que, diante da baixa remuneração, "tudo quanto se fizer ha de sair descosido, remendado, torto, como essas linhas que ahi ficam". Tal contexto de desvalorização da leitura de literatura transforma o ofício de produção literária em uma atividade de resistência por parte dos escritores, a quem cabe publicar, apesar de tudo ("Ainda assim, apezar dessa indiferença das classes ricas pelas artes, os nossos prosadores e poetas não esmoreceram. Não ha leitores, não ha livros; mas trabalha-se em segredo trabalha-se convictamente [...]").

No entanto, se há produção literária (e, pelo que se lê acima, ela não é pequena), há leitores. Uma prova disso é que, nesse mesmo jornal, durante todo o ano de 1891, publica-se o número diário de leitores que frenquentaram a biblioteca pública da Paraíba (fundada em 1857). Quase diariamente, encontra-se no jornal a seguinte 
entrada: "Bibliotheca Pública - Foi este estabelecimento frequentado hontem por 30 pessoas" (Jornal Estado da Parahyba, 03/04/1891, p. 3)

Essa frequência oscila: segundo publicado neste jornal em $03 / 03 / 1891$, por exemplo, ela foi de 31 leitores no dia anterior; e em publicação de 12/11/1891, registrase uma frequência de 10 leitores no dia anterior ao da publicação. Contudo, não se pode dizer que houve uma queda durante o ano, tendo em vista que no jornal de 13/11/1891 a frequência sobe para 20 leitores. O que se verifica, na verdade, nestes dados do Estado da Parahyba, é uma média que varia entre 20 e 25 leitores por dia na biblioteca, durante todo este ano de 1891. Considerando a população da cidade nessa época, as condições da instrução pública no Brasil e na Paraíba, bem como o número ainda elevado de analfabetos ${ }^{4}$, não podemos menosprezar esses números, nem tampouco considerá-los excessivamente baixos. Essa frequência dos leitores paraibanos se aproxima bastante daquela registrada algumas décadas antes, em 1861, na Biblioteca Nacional, e era considerada um "grande número", segundo relato de Moreira Azevedo:

Outr'ora achava-se a bibliotheca em um prédio mao, pequeno, escuro, porém existia no centro da cidade, na vizinhança das academias e das salas de aula. Era então grande o número de freqüentadores, 20 a 30 iam diariamente consultar livros na bibliotheca; mas transferida para o Largo da Lapa, diminuio muito o número de freqüentadores do estabelecimento: hoje já não são nem 20 nem 30, porém 7 ou 8. (AZEVEDO, 1861, apud SCHAPOCHNIK, 2002,p.291)

Pelas diferentes fontes utilizadas por pesquisadores percebe-se, então, que, já no séc. XIX, quando surgiu e se consolidou esse discurso da falta de leitura, havia muitos indícios que o invalidavam, mas que não parecem ter sido considerados: havia comércio de livros (BARBOSA, 2010); havia publicações de periódicos; havia bibliotecas públicas e particulares; havia intensa produção literária. A despeito do que diziam os viajantes estrangeiros e os homens das letras desse período, é insustentável a afirmação de que não havia leitores, de que aqui não se lia.

\subsection{A Biblioteca Pública Municipal de Campina Grande no início dos anos 1950: o que noticiavam os jornais?}

No item anterior, discutimos sobre o discurso da falta de leitura/leitores no Brasil. O tempo passou, mas esse discurso permaneceu. Atualmente, outras razões são convocadas para explicar esta falta. Em 2015, o Instituto Pró-Livro realizou a quarta edição da pesquisa Retratos da Leitura no Brasil. De acordo com os resultados desta pesquisa, apresentados em 2016, ao serem perguntados sobre as razões para não terem lido mais nos últimos 3 meses, os entrevistados alegaram falta de tempo (43\%), desinteresse ou o fato de não gostar de ler (5\%), a preferência por outras atividades (9\%), passando pelas dificuldades de compreensão ao ler (4\%), pelo preço do livro (7\%) e pela ausência de bibliotecas próximas (8\%), entre outras razões.

A negação da leitura que aqui se pratica é tão forte que em pesquisa realizada por Sousa (2008; 2009), os participantes, ao serem perguntados sobre suas leituras, afirmaram majoritariamente não gostarem de ler ou negaram ter o hábito da leitura, a

\footnotetext{
${ }^{4}$ Segundo dados publicados por Gomes (1983), a Paraíba contava, em 1872, com uma população de analfabetos que chegava a 334.953, contra apenas 41.273 alfabetizados, o que significa dizer que $89 \%$ da população paraibana era analfabeta. O número de analfabetos, evidentemente, tende a diminuir ao longo dos anos, mas, em 1920, ainda equivale a 68,8\% da população do Estado
} 
despeito de efetivamente serem leitores no seu cotidiano e a despeito de pertencerem a certos grupos (como o de estudantes e professores, por exemplo), cuja condição de nãoleitores seria contraditória, porque faz parte da própria inserção nestes grupos a pertença à categoria de leitores.

A Biblioteca Municipal de Campina Grande também foi alvo desse discurso da falta, especialmente no início dos anos 1950. Aproximadamente uma década após a sua fundação (que ocorreu em 1938), vamos reencontrá-la ainda como assunto de interesse dos jornais locais. Esse intervalo de tempo, embora a caracterize como uma instituição muito recente, se comparada a outras da mesma natureza, permite que possamos observar seecomo ela se consolidou na sociedade campinense.

Houve um período na sua história, mais especificamente no início da década de 1950, em que se lia com relativa frequência nos jornais locais o lamento a respeito da ausência de leitores neste espaço ou sobre a inadequação das leituras ali realizadas pelos seus poucos frequentadores. A euforia inicial registrada durante o ano de 1938 pelo jornal A Voz da Borborema(ESPÍNDULA, 2017) dá lugar, então, a reclamações diversas: quanto à estrutura da biblioteca, à ausência de leitores ou ainda quanto às suas leituras no interior da biblioteca. Geralmente, a insatisfação com a biblioteca já se manifesta no título de alguns desses textos, como, por exemplo: Biblioteca abjecta $(A$ Formação, outubro/1953); Biblioteca vive às moscas ( $O$ Globo, 14/07/1952); e Biblioteca, livros e traças ( $O$ Globo, 04/08/1952). Nestas três manchetes é possível perceber a avaliação negativa a respeito da instituição, tanto em relação às condições estruturais (que a fazem ser qualificada como "abjecta"), quanto em relação à frequência (já que ela estaria entregue às traças e às moscas).

O primeiro desses textos, a ser analisado aqui, foi publicado no jornal $O$ Momento, em 24 de setembro de 1950. Esse jornal, dirigido por um grupo de jornalistas pernambucanos (GAUDÊNCIO, 2012), faz um panorama desolador da biblioteca de Campina Grande e da leitura de uma forma geral, perpetuando o discurso de que aqui no país não se lê (ver Figura 1, a seguir). 
Figura 1 - Notícia do jornal O Momento (setembro/1950)

O MOMENTO - Domingo, 24 de Setembro de 1950

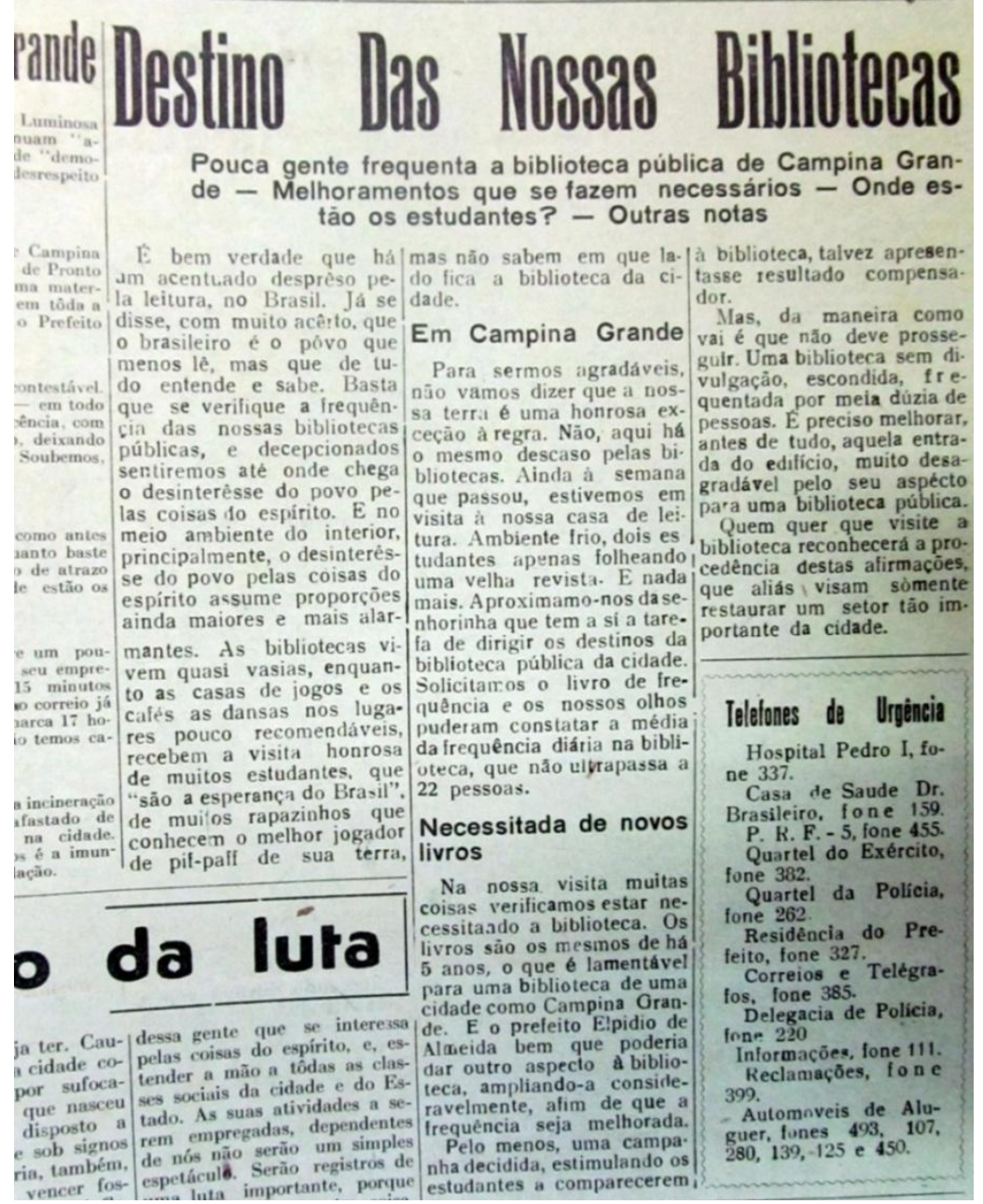

Fonte: Jornal O Momento (setembro/1950)acervo Museu Histórico de Campina Grande-PB.

No texto, intitulado "Destino das nossas bibliotecas", é possível encontrar de todos os discursos um exemplo: sobre a ausência de leitura e leitores, que transforma o Brasil num país que não lê; sobre a ausência de leitores na biblioteca municipal de Campina Grande, preterida em função de outros prazeres aparentemente mais atrativos aos jovens; sobre as condições de funcionamento da biblioteca, onde faltam livros e estrutura adequada - o que a torna menos convidativa, segundo o autor do texto (não identificado, já que a matéria não é assinada).

Enquanto a biblioteca é descrita como um lugar frio e abandonado, em situação oposta encontram-se "as casas de jogos e os cafés e as danças em lugares pouco recomendáveis", pois estes "recebem a visita honrosa de muitos estudantes". Essas observações levam a crer que a leitura não está entre as escolhas dos jovens nos seus momentos de lazer. Assim, não teria sido atingida a função inicial atribuída à biblioteca pelos letrados, que acreditavam ser esta instituição uma opção para as horas de "sadio deleite" dos campinenses. Essa imagem de biblioteca pública como um lugar disciplinador de comportamentos e práticas de leitura foi registrada por Hébrard (2009), na França de 1858. Ao propor que professores participassem de um concurso de ensaios sobre os benefícios de se fundarem bibliotecas públicas, o governo francês se deparou 
com opiniões convergentes nesse aspecto:

44 exposições acreditam que é um antídoto eficaz contra a ida a cabarés, cafés e lugares mal freqüentados, ou, ainda, contra o gosto pelo jogo; 46 exposições vêem aí o meio mais seguro para fazer recuar os livros ruins; 4 acrescentam aos livros ruins as superstições; [...] Apenas 5 pensam tornar, dessa forma, mais eficaz o ensino dos cursos de adultos e das escolas de domingo e 4 veem aí o meio de completar o trabalho de instrução do professor primário. (p. 12-13)

Aparentemente, em relação à BPMCG, foi criado o lugar, mas não o desejo/a necessidade dele, nas práticas cotidianas dos cidadãos.

A despeito de todas as ausências e faltas (de recursos materiais a leitores), a frequência diária atingia cerca de 22 pessoas, número semelhante ao registrado na Biblioteca Nacional (RJ) em seus primeiros anos e na Biblioteca Pública da Paraíba, no final do século XIX. Não seria este, então, um percurso corriqueiro na consolidação de instituições dessa natureza? É possível que sim, tendo em vista que, guardadas as devidas proporções, essa frequência coincidente foi registrada justamente nos momentos em que essas instituições ainda estariam se firmando na sociedade e todas elas com o papel de difundir práticas letradas ainda distantes de boa parte da população.

O jornal Formação, ligado ao Centro Estudantal Campinense (associação de estudantes, fundada, entre outros nomes, por Ronaldo Cunha Lima), também publicou texto sobre a biblioteca. Em edição de outubro de 1951, encontramos em suas páginas mais um registro das condições da biblioteca de Campina Grande neste início de década. Essa referência se dá através de uma matéria que cita a perspectiva de um estudante, Ronaldo Sindou Ramires, que escreve uma carta para o jornal a fim de denunciar as péssimas condições daquele espaço de leitura. É com base nesta carta que o jornal publica o texto "Sobre a biblioteca municipal", dividido em duas partes: a primeira, na página 2 e a segunda na página 4 da mesma edição. A seguir, transcrevemos os trechos que consideramos mais relevantes:

[...] O nosso companheiro missivista principia por lamentar profundamente o estada [sic] em que se encontra a Biblioteca Municipal. Diríamos, se fôssemos rigorosos no assunto, que praticamente não possuímos um centro de divulgação cultural desta natureza. Atualmente o que se vê ali, continua o colega Ramires, são livros cujo peso dos anos já recomenda um novo encadernamento... os vidros das estantes que se fazem tão necessários pela proteção que podem oferecer contra a poeira, os insetos, etc...estão em sua totalidade quebrados... [...]

Um tópico interessante que Ronaldo Sindou põe em evidência em sua criteriosa carta, é o fato de, pelo citado estado em que se encontra aquela Biblioteca, não oferecer esta o mínimo incentivo aos seus freqüentadores. [...] (Jornal Formação, outubro/1951, p. 2)

Assim como registrado em alguns momentos da história de outras bibliotecas (como a Biblioteca Pública da Bahia e a da Paraíba), na instituição de Campina Grande as condições de funcionamento provocam um descompasso entre a fundação da biblioteca e sua existência efetiva, uma vez que a precariedade da sua estrutura no decorrer dos anos faz com que os cidadãos afirmem que "[...] praticamente não possuímos um centro de divulgação cultural desta natureza". A insatisfação atinge desde a ausência de manutenção dos livros (que precisam ser encadernados novamente, pois são já antigos) até a precariedade dos móveis utilizados, o que ameaça danificar o 
acervo por não acomodá-lo adequadamente. Esses fatores são apontados, inclusive, como alguns dos que contribuem para o fato de a biblioteca não "oferecer [...] o mínimo de incentivo aos seus frequentadores".

Outra crítica dirigida à biblioteca nesse mesmo texto diz respeito ao acervo encontrado:

[...] Refere-se ainda Ramires à fraquíssima percentagem de livros didáticos, que absolutamente não satisfaz a procura valiosa dos estudantes esforçados; quanto às obras clássicas, seria um outro motivo para lamentações... [...]

Quem não gostaria de frequentar uma Biblioteca completamente modernizada, com suas secções bem divididas, oferecendo a tôdos oportunidades para conhecer, das mais recentes publicações às mais antigas obras já consagradas pela literatura universal? Não estamos a exigir todos os livros já editados no mundo, mas que seja ampliado o mais que se possa o patrimonio cultural da Biblioteca [...]. (Jornal Formação, outubro/1951, p. 2)

Então, a insatisfação passa pela ausência da manutenção do acervo existente, bem como pela falta de aquisições de livros para garantir a sua atualização, ou seja, a biblioteca negligencia, segundo o texto publicado, as obras já existentes e não realiza a compra de novas, o que contribui para a defasagem do acervo em todos os sentidos. Mas chama a atenção também, nesse texto citado, o destaque dado aos livros didáticos e à presença dos estudantes na biblioteca, o que justificaria ainda mais a necessidade de atualização a fim de que ela cumprisse sua função implícita: a pesquisa escolar.

No ano seguinte, em 1952, a biblioteca reaparece nos jornais, em dois textos publicados no periódico $O$ Globo, recém criado pelo jornalista Francisco Asfora ${ }^{1}$; em ambos, o foco se volta para o abandono no qual se encontra a biblioteca por parte dos leitores. Vejamos o primeiro, recuperado integralmente na Figura 2, a seguir:

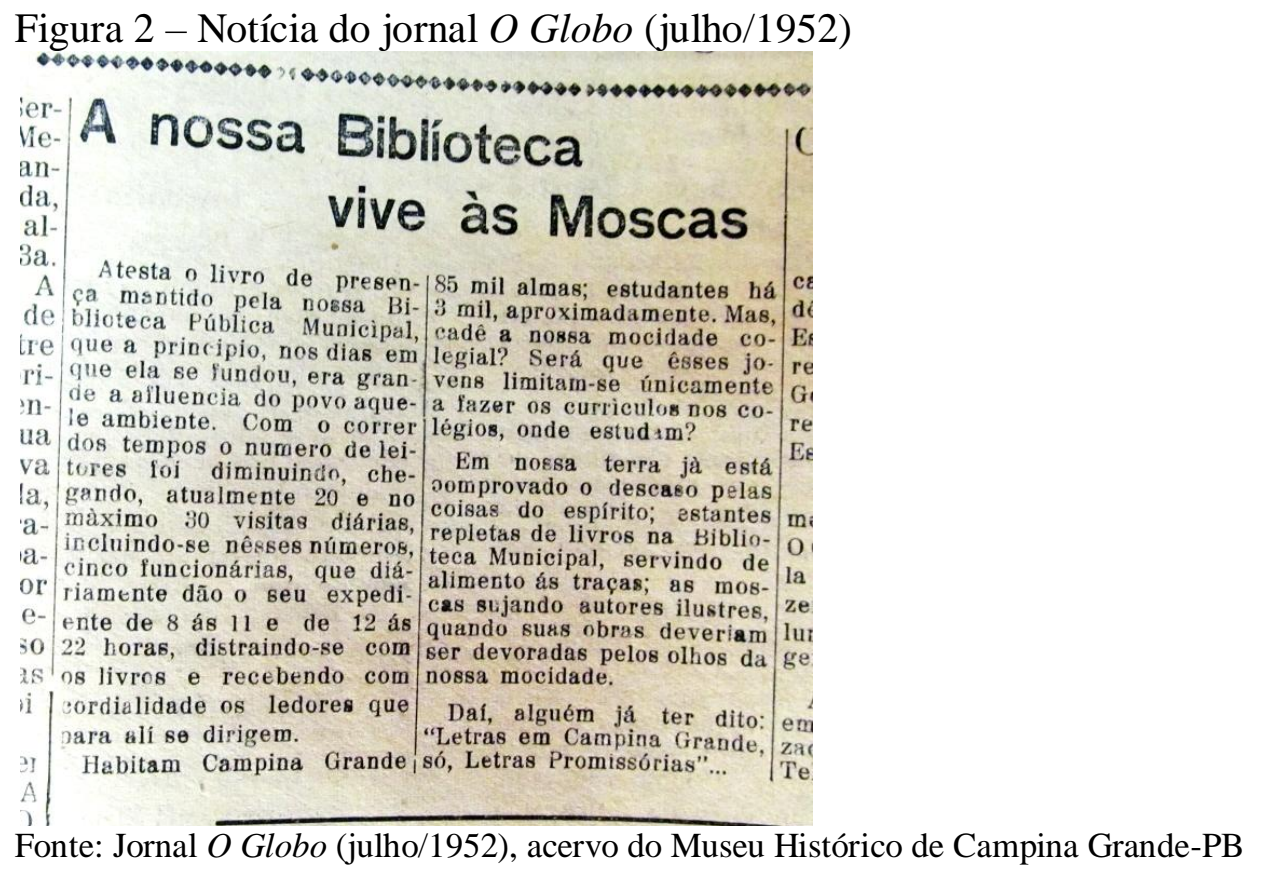

\footnotetext{
${ }^{1}$ Francisco Asfora foi um jornalista muito atuante na imprensa de Campina Grande, além de um líder estudantil. Pertencente a uma família ligada à política do Estado, exerceu cargos públicos e concorreu ao senado em diferentes ocasiões. Faleceu em novembro de 2013, aos 84 anos.
} 
Há, nesse texto, o registro da impressão de que a frequência da biblioteca diminuiu consideravelmente ao longo do tempo, apesar de o estabelecimento funcionar nos três turnos, com uma interrupção de apenas uma hora no atendimento oferecido ao público. Mais uma vez os estudantes aparecem como os frequentadores esperados, cuja sentida ausência na biblioteca é questionada no texto: se há tantos estudantes na escola formal, onde estão eles que não visitam aquele espaço de leitura? Uma hipótese interessante é a de que esses estudantes teriam acesso à leitura nas próprias escolas onde estudam; contudo, o autor do texto (não identificado pelo jornal) parece não estar convencido disso e atribui essa baixa visitação ao desinteresse da população às "coisas do espírito": "Em nossa terra já está comprovado o descaso pelas coisas do espírito; estantes repletas de livros na Biblioteca Municipal, servindo de alimento às traças; as moscas sujando autores ilustres quando suas obras deveriam ser devoradas pelos olhos da nossa mocidade". Muda-se, então, o teor da reclamação: já não faltariam livros, mas leitores. Estabelece-se assim o raciocínio de que, se não é por falta de livros, não é por falta de horário disponível, nem por falta de acesso à escola, os campinenses não frequentam a biblioteca por pura falta de interesse em relação à sua formação cultural.

Reforça-se, com isso, o argumento de que o brasileiro não lê ou não gosta de ler; ainda, especialmente, que Campina Grande assume sua vocação comercial tão propagada, mas não mantém a mesma dedicação no que diz respeito à leitura: "Letras em Campina Grande, só, Letras Promissórias". Como vimos no capítulo 1, essa é uma expectativa presente nos argumentos iniciais para a fundação da biblioteca: o ideal de que se atingisse o mesmo desenvolvimento cultural que o já alcançado nas áreas relacionadas ao comércio. Como se pode observar, na perspectiva do autor do texto citado, os interesses da população continuam distantes das práticas valorizadas pela camada letrada (consequentemente, distante da leitura de livros e da biblioteca), assim como verificamos nos textos publicados na década anterior.

O discurso sobre a leitura e a biblioteca oscila, então, entre uma falta e outra: em julho, a falta é de leitores que se interessem pelas "coisas do espírito"; no mês seguinte, em texto publicado no mesmo jornal, o alvo da insatisfação se volta para o descaso com que a Biblioteca vem sendo administrada: ainda sem prédio próprio e sem investimento na estrutura física e no acervo. Segundo o autor do texto (ver Figura 3, abaixo), tal descaso não tem outra justificativa a não ser a falta de interesse, uma vez que o governo federal, através do Instituto Nacional do Livro, faz remessas de obras para essas instituições. 
Figura 3 - Notícia do jornal O Globo (agosto/1952)

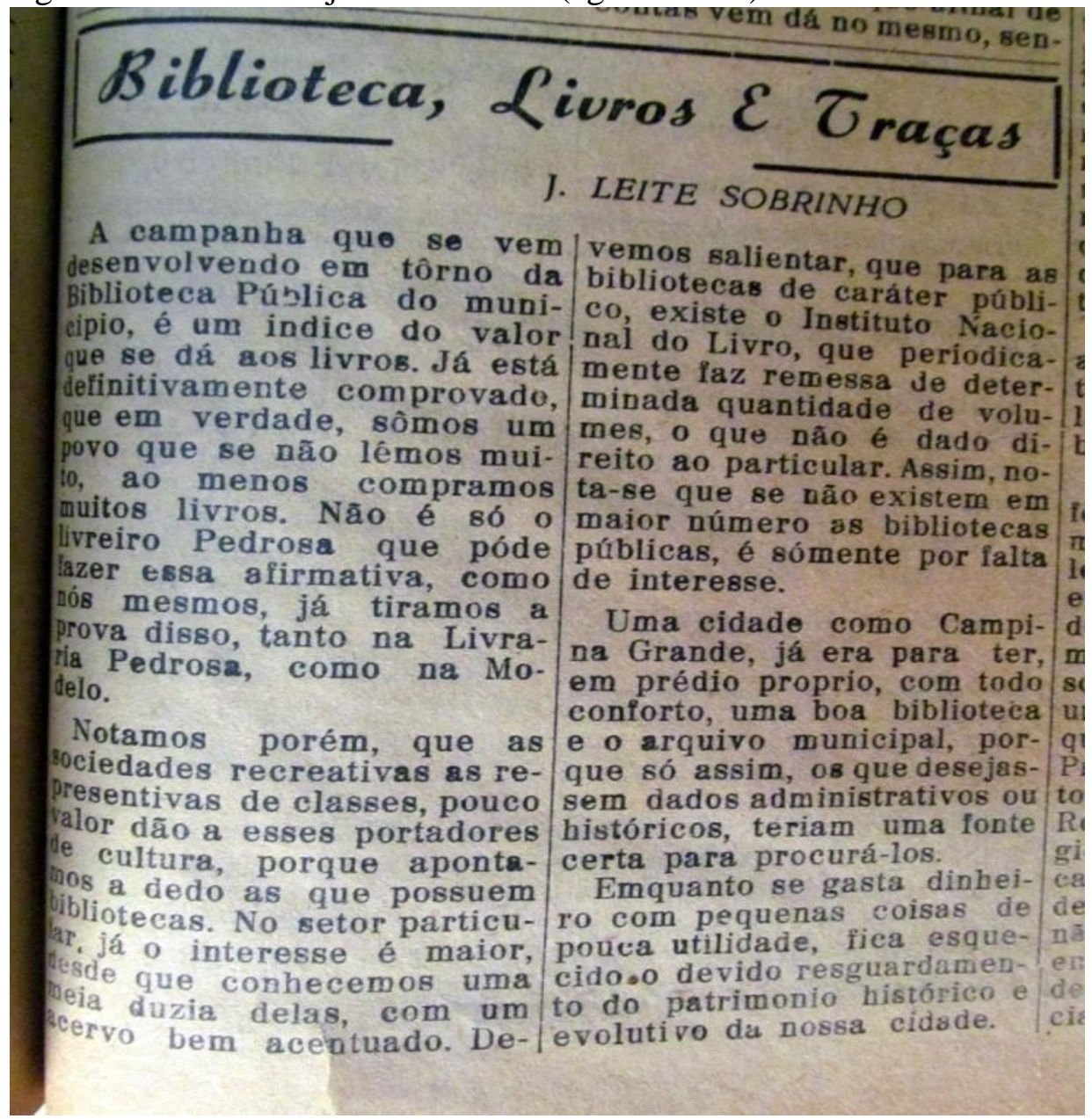

Fonte: Jornal O Globo (agosto/1952), acervo do Museu Histórico de Campina Grande-PB

Para José Leite Sobrinho, autor do texto acima, há leitores na cidade, embora ele traga para a discussão um contraste interessante: é possível que não se leia muito em Campina Grande, mas se compram muitos livros. Tal afirmativa remete à relação sempre presente entre a posse de livros e o status social. Livros sempre foram produtos caros, cuja compra não estava acessível para boa parte da população menos privilegiada (isso se aplica a qualquer época e lugar), então, poder comprá-los era uma forma de construir uma imagem positiva de si mesmo por dois fatores: o financeiro, porque demonstrava o poder de compra; e o cultural, porque inseria o comprador em uma elite que valorizava bens culturais como o livro.

Além disso, os lugares de compra de livros (como as livrarias Modelo e Pedrosa, citadas no texto) eram também lugares de sociabilidade, onde os campinenses se encontravam para falar sobre suas leituras, escritas, mas também para se manterem informados sobre os assuntos cotidianos da vida na cidade (GAUDÊNCIO, 2012; COSTA, 2012). Ir às livrarias, falar sobre livros e autores, eram práticas cultivadas pela elite letrada campinense e consideradas elegantes por este grupo social. O próprio livreiro Pedrosa foi, segundo Costa (2012), o responsável por criar uma rede de discussão em torno dos livros, rede que não se limitava à sua livraria, mas culminava nela: por onde passava, ele estava sempre tecendo comentários sobre os livros que lera, sobre os últimos lançamentos que chegaram à sua livraria e sobre as figuras ilustres que ali iam para conversar com seus pares ou para lançar suas publicações. Indiretamente, 
ele ia fortalecendo seu negócio, mas também estimulando a prática da leitura na cidade. Não por acaso, em 1953 ele lançaria o Edifício do Livro, grande empreendimento no setor, com instalações amplas e modernas para atender o público, numa das ruas mais importantes do centro da cidade: a Maciel Pinheiro. Assim, aqueles que ouviam seu apelo e faziam do livro "seu melhor amigo" (slogan adotado na campanha de divulgação da livraria), podiam ali encontrar-se e atualizar-se.

[...] Pedrosa conseguia aglutinar num só espaço variedades em livros, lançamentos, cultura, lazer, intelectuais, pessoas interessantes para flertes, para retretas, para bebericar, além de ter um "precinho mais em conta". A livraria era mais que um local de vender livros e material escolar. Era um ponto de encontro. Isso fazia a diferença. $\mathrm{O}$ sujeito frequentava o ambiente não apenas para comprar material, mas para consumir as conversas, consumir o espaço, como diria Certeau. (COSTA, 2012, p. 68)

O livreiro Pedrosa ainda criou um programa de rádio, veiculado pela Rádio Borborema sempre ao cair da noite (por volta das $18 \mathrm{~h}$ ), no qual comentava obras lidas e publicações recentes. Essas atitudes, sem dúvida, inseriam na vida da população um contato, ainda que indireto, com o mundo dos livros e da leitura. Todas essas estratégias funcionavam bem para que ele atingisse seu objetivo de vender livros, pois se era um hábito elegante da "gente culta", todos queriam com ele se identificar. Assim, entre uma conversa e outra, ele ia vendendo livros e também moldando gostos: "[...] o próprio livreiro era um veículo de apresentação da leitura [...]. Ao escolher determinadas obras para colocar em suas prateleiras, Pedrosa veiculava sobre o consumidor um discurso de controle, de seleção de leituras, de organização, de domínio" (COSTA, 2012, p. 49).

Por outro lado, a afirmativa de que em Campina Grande se vendiam muitos livros, apesar de não se ler muito, também parece reconhecer, implicitamente, que comprar um livro nem sempre significa lê-lo e que essa prática de compra para ostentação, tão antiga (conforme comprovam, entre outros, os estudos de Chartier (1999b)), também poderia ser recorrente naquele momento em Campina Grande. É possível que nem toda essa gente polida e elegante que frequentava a livraria Pedrosa e se transformava em consumidora de seus produtos, especialmente dos livros, fosse necessariamente leitora. Afinal, ir à livraria estava relacionado também a outros interesses de sociabilidade e não apenas à leitura: dirigir-se àquele local significava encontrar pessoas, conversar, socializar-se tanto quanto seria possível indo a um café. Talvez a pouca frequência dos leitores reclamada no texto jornalístico citado se dê justamente pela ausência de uma rede de sociabilidade que envolvesse a biblioteca municipal e a colocasse como um lugar privilegiado de encontro entre os campinenses, em torno do livro e da leitura.

Ainda no texto publicado por José Leite Sobrinho no jornal $O$ Globo, registrase o lamento sobre a falta de bibliotecas na cidade, uma vez que, segundo ele, as associações recreativas e as representativas de classe não as têm e a pública, conforme já comentamos, não está em boas condições. Tudo, portanto, compete contra a biblioteca: não há livros, nem instalações adequadas, consequentemente, não há leitores.

Um ano depois, a situação parece não ter melhorado, uma vez que o jornalista Nazário Pimentel, inicia assim o seu texto intitulado A Bibliotéca Municipal:

Pequena, isolada, sem conforto, sem livros, sem revistas, sem jornais, assim está a Biblioteca Municipal de Campina Grande. É na verdade uma vergonha para a décima terceira cidade do Brasil, não possuir uma BIBLIOTECA a altura de suas necessidades (Jornal do Estudante, agosto/1953, p. 4). 
A biblioteca é, então, caracterizada pela falta: tudo falta, inclusive os leitores (certos):

Biblioteca está abandonada por tudo, procurada apenas por estudantes folgadões, que ali vão passar a tarde lendo histórias de Carochinha e, contos policiais.

O que esta biblioteca precisa é de dirigentes e de livros, não livros de carochinhas nem tão pouco livros policiais e sim, livros instrutivos (pois tem muito pouco) livros que abram o espírito deste povo impetuoso como o de nossa mocidade. (Jornal do Estudante, agosto/1953, p. 4)

Desta vez, há o reconhecimento de que os leitores existem, mas eles são caracterizados como "estudantes folgadões". Ao usar essa expressão, o autor reafirma a relação entre a leitura na biblioteca e o vínculo com a educação formal (uma vez mais são os estudantes que aparecem como leitores deste espaço). Ao mesmo tempo, tendo em vista o perfil desses frequentadores "folgadões", considera que a biblioteca está "abandonada por tudo", ou seja, apesar de existirem, esses leitores são condenados à invisibilidade, devido às suas práticas supostamente inadequadas: ir "ali passar a tarde lendo histórias de Carochinha e contos policiais". Não sabemos ao certo a que leituras ele se refere ao mencionar "histórias da Carochinha" e "contos policiais" como as escolhas desses leitores, mas sem dúvida elas estão no campo da ficção, o que é considerado como inadequado por não contribuir, segundo o autor, para a boa formação desses estudantes.

Tal é a recusa por essas leituras que Nazário Pimentel, a um só tempo diretor e articulista no jornal, chega a afirmar que caberia à biblioteca alterar o tipo de obras a serem oferecidas: segundo ele, "não livros de carochinhas nem tão pouco livros policiais e sim, livros instrutivos (pois tem muito pouco) livros que abram o espírito deste povo impetuoso como o de nossa mocidade". Em outras palavras, a "censura" ou o direcionamento para as leituras adequadas deveria partir da administração da biblioteca, ao escolher para seu acervo obras que realmente contribuíssem para a boa formação dos seus usuários, na perspectiva defendida no jornal.

Esse posicionamento acerca das leituras e dos leitores não é exclusividade do autor da matéria de jornal mencionada; não é sequer uma novidade daquela época. Apenas para citar um exemplo, em 1876, o diretor da Biblioteca Nacional brasileira afirma o seguinte:

É egualmente sabido que nossa mocidade se occupa mais em geral da leitura de novellas, poesias ligeiras e peças escandalosas do que da consulta de obras de elevado valor scientífico e litterario; ora não é também este o logar adequado para similhantedistracções, e por isso não existem aqui os tomos ambicionados pela imaginação incandescente e transviada dos moços a quem me refiro. (Relatório do Diretor da Biblioteca Nacional, 1876, apud SCHAPOCHNIK, 2002, p. 293).

Apesar de ser um discurso recorrente, os livros que o concretizavam e serviam para "abrir o espírito" no final do século XIX não eram os mesmos na década de 50 do século XX (período em que a referida notícia é publicada) e não seriam os mesmos na atualidade. Há, inclusive, nos dias de hoje, uma maior valorização de um tipo de leitura (de literatura) e de uma função da leitura (por prazer) que não se verificava nesses dois períodos comentados. Esses fatores, entre outros, interferem na avaliação do que se considera como obra ideal para "abrir" ou "formar o espírito" a cada momento. 
Ainda assim, essa forma de caracterizar a Biblioteca Pública Municipal (fortemente relacionada a uma visão depreciativa das bibliotecas de forma geral) e também os seus leitores, demonstraque os usos efetivamente realizados pelos seus frequentadores não eram aqueles imaginados pela elite intelectual que a fundou. A euforia inicial pela criação da biblioteca é substituída agora pela recusa aos usos "ilegítimos" que a população (não necessariamente membros da elite, mas possivelmente também estes) passou a fazer da biblioteca, "corrompendo", na perspectiva dos letrados, o destino inicialmente pensado por eles e analisado no capítulo anterior. A biblioteca passou a ser território de visitantes cujas práticas não agradavam.

Ainda no ano de 1953, Garibaldi Dias de Sousa publica no jornal Formação o texto intitulado "Biblioteca abjecta", recuperado na Figura 4, a seguir.

Como já aponta o próprio título do texto, a biblioteca é descrita como uma instituição abandonada e ineficaz: "De Biblioteca só tem mesmo o nome, porquanto os móveis são decrépitos, os livros rasgados e empoeirados, e o barulho ensurdecedor. Está ela localizada num local em que o sujo, a poeira, as aranhas com suas teias, são quem mandam [...]". Aparece mais uma vez a ideia de que ela não existe de fato, pois o que existe sequer merece o nome de biblioteca, o que motiva o apelo no final do texto para que a Secretaria de Educação e Cultura contribua para o "engrandecimento cultural de Campina Grande, dotando-a de uma Biblioteca que seja na realidade uma Biblioteca". Como vimos anteriormente, essa tensão entre o ato de fundação e a existência concreta de uma biblioteca em condições de funcionamento também ocorreu com outras instituições, a exemplo da Biblioteca Pública da Paraíba (no final do século XIX e início do XX).

Merece destaque ainda, nesse texto de Garibaldi Dias de Sousa, a referência à relação entre a biblioteca e os estudantes, uma vez que ele defende uma instituição que "atendesse as necessidades dos estudantes campinenses", argumento bastante recorrente na história desse espaço de leitura. Além disso, segundo o autor, os estudantes deveriam se "deliciar" com alguns autores nacionais e estrangeiros, o que sugere uma ideia de leitura para fruição e não apenas como fonte de pesquisa escolar. Mantém-se a ideia de que há "bons" autores para serem lidos a fim de formar o espírito desses estudantes; ou seja, mesmo quando a leitura surge como possibilidade de fruição, não é abandonada, ainda que implicitamente, a sua função de formação, uma vez que não são sugeridos quaisquer autores, mas sim aqueles já consagrados por uma tradição literária: Balzac, Camões, Daudet, Humberto de Campos, Joaquim Nabuco e Machado de Assis. 
Figura 4 - Notícia do jornal Formação (outubro/1953)

F O R M A C A O Outubro de 1953

\section{BIBLIOTECA ABJECTA}

Garibaldi Dias de Sousa

Émeu propósito fo- tura Municipal, não|lizada num local em calizar nêste artigo, parece merecer a a- que o sujo, a poeira, um problema que há tenç̃o daquela re- e as aranhas com su muito tempo aflinge partição, pois que há as teias, são quem o meio cultural de muito vive despre- mandam. Não seria Campina Grande. E zada, de uma manei- preciso, que a Secre um problema vetusto, ra como não se des- taría de já debatido por di- preza nem uma pe- Cultura versas vêzes, masque vertida. De Bibliote- cultara Municipal, doeu o quero lembrar vertida. De Bibliote- tasse Campina Graneu só tern mesmo o de de uma Biblioteração por mais uma vez. nome, porquanto os ca semelhante a do rés A Biblioteca Muni. móveis são decrépi-. Vaticano on a Muni-

fin cipal de Campina tos, os livros rasga-cipal do Rio de Ja-

Grande, entregue a dos e empoeirado- cipal do Rio de Jaio de direção da Secretaría e o barulho ensurde- nas, uma que atenatasse de Educação e Cul-lcedor. Está ela loca- desse às necessida-

a de

lisรão

valdo

tamos

a que

ami-

tanto,

nchar

"Silêncio"

Não te digo, nem direi... Mas penso Que o meu olhar quando aos teus olhos pousa. Te revela em segrêdo alguma cousa. Alguma cousa dêste amôr imenso!

Minha bôca, bem vês, como uma lousa E muda, embora, num desêjo intenso, Arde o meu coração com um incenso Envolto no mistério em que repousal

Que outros proclamem seu amôr em frases, De fôgo alcando a vóz internecida. Chêios de vozes e expressões falazest.

Eu não... Nada te disse e nem le digo. Mas sabes que este amor é minha vida. $E$ que $\mathrm{em}$ silencio MORRERA comigo.

Campina Grande, Paraiba des dos estudantes campinenses que assim poderiam se deliciar com as leituras de autores nacionais e estrangeiros. Ai, o estudante podeA1, o estudante poderia familia rizar-se tanto com Balzac, com Camões ou com Daudet. Familiazarse-ia também com Humberto de Cam Homberto de Campos, Joaquim Nabuco e Machado de Assis.

Eis porque, eu lanço .0 nueu apélo à Se cretaria de Educacão e Cultura Municipgl com o fim de que ela volva os olhos ra o problema para oproblema do engrandecimento cultural de Campina Grande, dotando-a de uma Biblioteca que seja na realidade, uma Bi-

0

Fonte: Jornal Formação(outubro/1953), disponível no acervo do Museu Histórico de Campina Grande

Para finalizar, um dado que também merece atenção é a referência, em três dos textos jornalísticos recuperados, à ideia de que o desenvolvimento cultural de Campina Grande (simbolizado pela biblioteca) não acompanha o desenvolvimento econômico da cidade, alcançado especialmente na área do comércio, o que fica mais evidente, por exemplo, no seguinte trecho:

Até quando, ó prefeitos que passam, esperaremos nós pela tão almejada Biblioteca Municipal? Não vêdes que esta é a Rainha da Borborema, a Capital dos Sertões Nordestinos?

Eu, cá com meus botões fico pensando: sim, talvez seja Rainha, mas uma Rainha que em cuja corôa traz um ocioso símbolo do Comércio! Talvez seja uma Capital, mas pela simples razão de habitar em seu seio um avultado número de capitalistas. (Jornal Formação, Outubro/1951, p. 2) 
A irônica afirmativa de que "Letras em Campina Grande, só Letras Promissórias" (Jornal $O$ Globo, julho/1952) corrobora a crítica ao fato de que os investimentos existentes são predominantemente destinados a outras áreas da administração pública, ficando a cultura (consequentemente, a biblioteca) abandonada e condenada a funcionar de maneira precária. Como afirma José Leite Sobrinho: "Enquanto se gasta dinheiro com pequenas coisas de pouca utilidade, fica esquecido o devido resguardamento do patrimônio histórico e evolutivo da nossa cidade" (Jornal $O$ Globo, agosto/1952). Tal é o estado em que se encontra a biblioteca, que o autor do texto se pergunta até quando "esperaremos nós pela tão almejada Biblioteca Municipal?", pondo em evidência que ela existia de direito, mas não de fato.

Portanto, a Biblioteca Pública Municipal de Campina Grande, em pouco menos de 15 anos se converte de grande realização do governo em instituição abandonada, onde tudo falta: prédio próprio, livros, móveis, estrutura adequada e até mesmo leitores. Estes são em número reduzido na década de 1950, segundo os jornais da época. E, mesmo quando existem, são condenados a certa invisibilidade, porque suas práticas (o que leem e como leem) são consideradas inadequadas, afinal, nessa perspectiva, ir para a biblioteca ler "histórias da carochinha ou contos policiais" é o mesmo que deixá-la abandonada, pois significa desvirtuar este espaço de sua função mais nobre: a formação do espírito da mocidade, através de leituras instrutivas. Assim os leitores, quando a armadura não lhes serve,como o cavaleiro inexistente de Calvino ${ }^{5}$, deixam de existir aos olhos da sociedade: tornam-se leitores inexistentes. E, no entanto, eles existiram.

\section{Considerações Finais}

Apesar de termos recuado quase 70 anos no tempo, para abordamos o tema da existência de leitores em Campina Grande-PB, o que se percebe é que essa negativa registrada nos jornais poderia facilmente ser identificada atualmente, na fala de diferentes sujeitos envolvidos ou não com a leitura. Ao que parece, faz parte de um senso comum dizer que "aqui não se lê". Se trocássemos os nomes dos jornais, as suas respectivas datas e atualizássemos a ortografia, seria provável que o mesmo quadro descrito nos textos analisados fosse reconhecido como pertencente à situação atual: bibliotecas vazias e em condições precárias, leitores em número reduzido, leituras inadequadas, etc. Contudo, assim como ocorria na década de 1950, essa percepção, hoje, só contaria uma parte da história e, por isso mesmo, representaria uma visão parcial dos fatos sobre a leitura no município.

Para além de pesquisas, como a que realizamos sobre os leitores da Biblioteca Pública Municipal da cidade, que comprovam a existência de leitores dando vida a este espaço de leitura, o contexto não poderia ser mais favorável à prática da leitura: há diversas escolas e universidades, muitas delas com bibliotecas ou salas de leitura; há uma biblioteca municipal que continua em funcionamento, além de bibliotecas comunitárias (como aquelas instaladas nos bairros das Malvinas e do Tambor) e bibliotecas ligadas a associações de trabalhadores (como a do SESC); há vários clubes de leitura, que se reúnem regularmente em diferentes lugares; há blogueiros locais que publicam sobre livros/leituras nas redes sociais; há booktubers que conseguem um bom alcance com seus canais; e há os sebos e livrarias, algumas delas com programação

\footnotetext{
${ }^{5}$ Referência ao personagem principal de O Cavaleiro Inexistente, obra publicada por Ítalo Calvino, em
} 1959. 
permanente de contação de histórias. E estou apenas citando alguns elos desse circuito de contato com a leitura, correndo o risco de deixar de fora as bibliotecas particulares, a prática de empréstimos pessoais, o comércio de materiais de leitura em feiras livres ou eventos (acadêmicos ou não, incluindo os pontos de vendas fixos nas universidades), as feiras de troca de usados, entre tantas outras formas de acesso. Como sustentar toda essa rede, se não houvesse leitores? Impossível.

É preciso deixar claro, no entanto, que a formação de um público leitor precisa ser preocupação permanente, pois, se reconhecemos que há um contexto favorável na cidade no que diz respeito à promoção da leitura, os índices de leitura ainda não são os sonhados: sempre podemos melhorá-los. Mas é importante que essa busca por conquistar mais leitores não negue o caminho já percorrido, nem os avanços alcançados até o momento. E, neste sentido, a existência da FLIC é um exemplo paradoxal da realidade atual: ao mesmo tempo, nos dá alento e aponta para o fato de que, sim, há leitores em Campina Grande; mas também revela que ainda há muito por fazer. Por essa razão, que esta história esteja apenas começando e que um dia, anos à frente, estejamos numa de suas edições, discutindo os impactos que a feira trouxe para o desenvolvimento da leitura na cidade.

\section{Referências}

ABREU, M.(org.). Leitura, História e História da leitura. $1^{\text {a }}$. reimpressão. São Paulo: Fapesp, 2002.

Diferença e desigualdade: preconceitos em leitura. In: MARINHO, M. (org.). Ler e navegar: espaços e percursos da leitura.Campinas-SP: Mercado de Letras, 2001. p. 139-157.

BARBOSA, S. de F. P. Os intermediários da leitura na Paraíba do Oitocentos: livreiros e tipógrafos. In: BRAGANÇA, A.; ABREU, M. (orgs.). Impresso no Brasil: dois séculos de livros brasileiros. São Paulo: Unesp, 2010.

CERTEAU, M. de. A invenção do cotidiano: artes de fazer. 12. Ed. Petrópolis, RJ: Vozes, 1994.

COSTA, Fernanda Pires da. A Livraria Pedrosa-Casa do Saber: a emergência de uma cidade letrada e de leitores. Universidade Federal de Campina Grande. Programa de Pós-Graduação em História. Dissertação de mestrado. Setembro/2012.

ESPÍNDULA, Danielly Vieira Inô. UmaBiblioteca e seus leitores: percursos de uma história. Jundiaí, SP: Paco Editorial, 2017.

GAUDÊNCIO, Bruno Rafael de Albuquerque. Da academia ao bar: círculos intelectuais, cultura impressa e repercussões do Modernismo em Campina Grande - PB (1913-1953). Universidade Federal de Campina Grande. Programa de Pós-Graduação em História. Dissertação de mestrado. Março/2012.

GINZBURG, C. Mitos, Emblemas, Sinais: morfologia e história. 2. Ed. São Paulo: Cia das Letras, 2007. 
GOMES, S. de C. Bibliotecas e sociedade na primeira república. São Paulo: Livraria Pioneira, 1983.

HÉBRARD, J. As bibliotecas escolares: entre leitura pública e leitura escolar na França do II Império e da III República. Campinas-SP: Mercado de Letras, 2009.

LAJOLO, M.; ZILBERMAN, R.A formação da leitura no Brasil. 3. Ed. São Paulo: Ática, 2009.

OLIVEIRA, Z. C. P. de. A biblioteca "fora do tempo": políticas governamentais de Bibliotecas Públicas no Brasil (1931-1989). Tese de doutorado. Curso de pós-graduação em Ciência da Comunicação. Escola de Comunicação e Artes. Universidade de São Paulo, 1994. 221p.

RETRATOS DA LEITURA NO BRASIL. São Paulo: Institudo Pró-Livro, 2016. Disponível em <http://prolivro.org.br/>. Acesso em: jan, 2019.

SCHAPOCHNIK, Nelson. Das ficções do aquivo: ordem dos livros e práticas de leitura na biblioteca da corte imperial. In: ABREU, M. (org.). Leitura, História e História da Leitura. 1'. Reimpressão. São Paulo: Fapesp, 2002. p. 273-311.

SCHOPENHAUER, A. A arte de escrever. Porto Alegre: L\&PM, 2010.

SOUSA, Maria Ester Vieira de. Histórias de pesquisas em leitura. In: SOUSA, Maria Ester Vieira de, ASSIS, Maria Cristina (orgs.). Pesquisa em Língua Portuguesa: da construção do objeto à perspectiva analítica. João Pessoa: Editora da UFPB/UFPB virtual, 2011. p. 137-168.

Desnaturalizando o discurso sobre a leitura. In: ANAIS do VI Congresso Internacional da ABRALIN. João Pessoa: Idéia, 2009

Leitura de professores e alunos: entre o prazer e a obrigação. In: Encontro Internacional de Texto e Cultura. Fortaleza: UFC, 2008.

Recebido em 14 de janeiro de 2019

Aceito em 23 de fevereiro de 2019 